\title{
Developing an Integrated Tourism Production Model with Digital Technologies (DT) for Small Medium Food Enterprise (SMFE) in Post-COVID-19 Era: A Conceptual Perspective
}

\author{
Wan Mohd Adzim Wan Mohd Zain, Muaz Azinuddin, Nur Shahirah Mior \\ Shariffuddin, Ahmad Puad Mat Som
}

To Link this Article: http://dx.doi.org/10.6007/IJARBSS/v11-i11/11355

DOI:10.6007/IJARBSS/v11-i11/11355

Received: 20 September 2021, Revised: 22 October 2021, Accepted: 10 November 2021

Published Online: 23 November 2021

In-Text Citation: (Zain et al., 2021)

To Cite this Article: Zain, W. M. A. W. M., Azinuddin, M., Shariffuddin, N. S. M., \& Som, A. P. M. (2021). Developing an Integrated Tourism Production Model with Digital Technologies (DT) for Small Medium Food Enterprise (SMFE) in Post-COVID-19 Era: A Conceptual Perspective. International Journal of Academic Research in Business and Social Sciences, 11(11), 1455 - 1458.

\section{Copyright: (c) 2021 The Author(s)}

Published by Human Resource Management Academic Research Society (www.hrmars.com) This article is published under the Creative Commons Attribution (CC BY 4.0) license. Anyone may reproduce, distribute, translate and create derivative works of this article (for both commercial and non0-commercial purposes), subject to full attribution to the original publication and authors. The full terms of this license may be seen at: http://creativecommons.org/licences/by/4.0/legalcode

Vol. 11, No. 11, 2021, Pg. 1455 - 1458

Full Terms \& Conditions of access and use can be found at http://hrmars.com/index.php/pages/detail/publication-ethics 


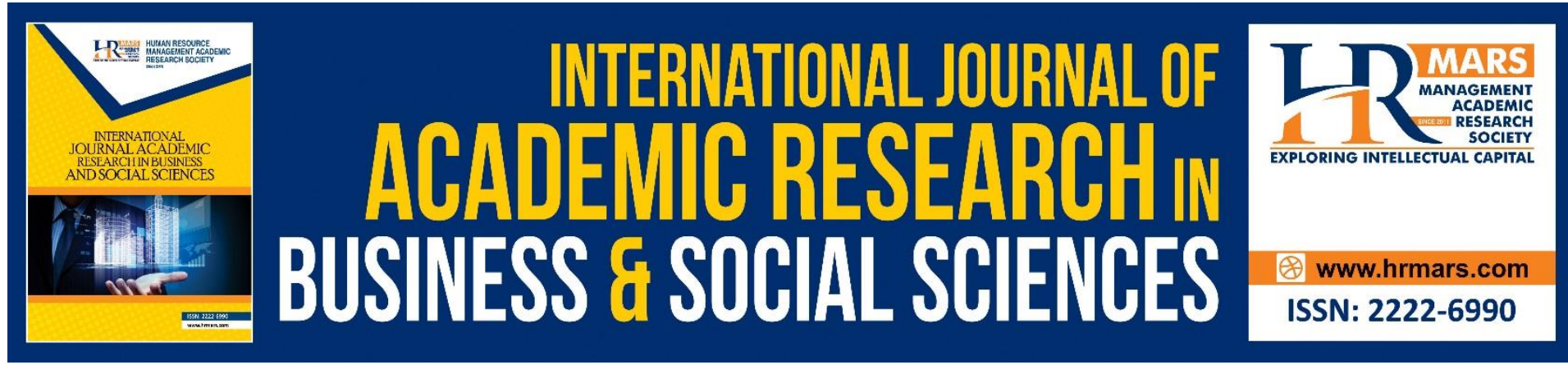

\title{
Developing an Integrated Tourism Production Model with Digital Technologies (DT) for Small Medium Food Enterprise (SMFE) in Post-COVID- 19 Era: A Conceptual Perspective
}

\author{
Wan Mohd Adzim Wan Mohd Zain, Muaz Azinuddin, Nur \\ Shahirah Mior Shariffuddin, Ahmad Puad Mat Som \\ Faculty of Applied Social Sciences, Universiti Sultan Zainal Abidin, Kuala Nerus, Terengganu, \\ Malaysia \\ Email:wmadzimz@unisza.edu.my
}

\begin{abstract}
This paper addresses the concept of Digital Technologies (DT) in retaining local food to achieve long-term tourism resilience. Particularly, this study focuses on food tourism production involving Small Medium Food Enterprise (SMFE) to generate post-COVID-19 economic activity, and how to increase hedonistic tourist experiences by proposing a model that integrates local food tourism production functions with DTs. The model represents a crucial mechanism from resources management to product outputs; connecting each stage with digital initiatives to aid endurance of SMFEs. Furthermore, this study intends to establish an innovative evolutionary stimulus for SMFEs in retaining regional tourism income and to configure robust and flexible foundations for future crisis management. DTs integration will allow SMFEs to implement both dynamic learning approaches and innovative capabilities. Another important aspect of this research is to interact and address the Sustainable Development Goals (SDG) with focus to utilize technology in food tourism by fostering sustainable innovation, ensuring continuous production patterns and strengthening partnerships for sustainable tourism development.
\end{abstract}

\section{Introduction}

Food tourism is considered a sustenance for regional destination development. Unlike general tourism, food tourism posits that tourists can obtain unforgettable, unique, and cultural experiences through food tourism resources or food experiences (Chen and Huang, 2018). However, the COVID-19 pandemic severely impacted tourism businesses. There are calls to regenerate and equip Small Medium Food Enterprises (SMFE) to move beyond 'business as usual' in order to face the major tourism shifts in years to come. To add, the pandemic requires tourism to push local food as a major tourism product that would both help tourist destinations as well as renew the domestic market. 
The turbulent COVID-19 crisis has deeply harmed the tourism sector and as the outbreak will be around for some time, the overall economic activities of the sector have been reduced to a small fraction of what they used to be prior to the pandemic. Moreover, the pandemic has generated severe communal and economic concerns at all levels, including social aversion, occupational hazard, supply chain failures, stock market collapses, lockdowns, and issues linked with deglobalization (Crick and Crick, 2020). Evidence generated by SME Malaysia (2020), based on 15,627 business setups show that more than $50 \%$ of SMEs fear experiencing more than half a million ringgit losses within six months from March to Sept 2020. It is evident how the pandemic caused major downfalls for SMEs in adjusting to this magnitude of a crisis because of resource scarcity, required expertise and knowledge, and low awareness level (Islam et al., 2021).

Although crises are by no means new to tourism, the impact of COVID-19 at least from an economic point of view, has so far been more devastating than any other crises in recent history (Hall et al. 2020; UNWTO, 2020). As a result, the pandemic has led to a massive change not only from an economic definition, but in consumption (consumer/tourist) behaviours and patterns. The current crisis depicts signs that it is not only different and more deteriorative than previous crises, but will have profound and long-term changes to tourist socio-economic activity and industry by challenging the current values and system. At this point, what is still lacking is knowledge about how the crisis can foster industry change, how tourism businesses can convert this crisis disruption into transformative innovation, and how to conduct research and development (R\&D) that can enable, inform, and shape the rethinking and resetting of [the] next normal (Sigala, 2020).

So far, research on the crises that SMEs experience and how the organisational actors interact during crises are limited (Cucculelli \& Peruzzi, 2020; Mayr, Mitter, \& Aichmayr, 2017). More specifically, existing research has overlooked the identification of appropriate actions and strategies taken by leaders in times of crisis and the effectiveness of those strategies based on the firm's capabilities (Bundy et al., 2017) mainly in the context of SMEs (Randall, 2018). As such, the crisis has brought forth how SMFEs in tourism will need to act decisively in order to take advantage of the recovery phase. Tourism production has to be vigilant when accommodating these new norms through improving financial resilience, business models, and technological fluency (Chan,2020). More importantly, digital technology plays a central role for SMFEs to stay viable in the tourism market (Sidhu, 2020). Nevertheless, there is a dearth of research on digital technology in food tourism. Although there are several attempts to explore the Digital Content Marketing (DCM), which is assumed to be an essential element of digital marketing in food tourism (Bu et al., 2020; Mkono and Tribe, 2017), this assumption has not been empirically investigated. Therefore, the objectives of this conceptual study are:

- To understand the importance of DT readiness amongst SMFEs.

- To propose an integrated model of DT and tourism production process for food tourism development.

Correspondingly, there are significant signs that IT has been widely used, adapted and developed to address some of the pressing problems; It can be said that technology has become a major factor in building resilience in tourism (UNWTO, 2020; Hall et al. 2017). It 
appears to be highly effective for food tourism recovery, even essential in confronting the aforementioned pandemic-related problems.

\section{Food Production and Food Tourism}

Local food is one of the key segments of destination and tourism development. This context of destination and tourism development is emphasized by Sotriadis (2015) in which he suggests the primary function of destination development should be to enrich and differentiate the destination's food supply process. When food is mutually linked with destination, it then becomes directly involved with local planning, developing, and marketing food as a tourism commodity. To add, the linkage between food and destination benefits other sectors/segments including agriculture, fisheries, heritage, and culture (Robinson and Getz, 2014). In this notion, the food tourism supply chain is linked with local producers, tourism-related business, and establishing a network within the industry at all levels (Sotriadis, 2015).

The link between food production and tourism is of increased interest amongst tourists. Especially those who are looking for food quality and traditional gastronomy, which indicates the strong intersectoral cooperation between production and tourism to form a food tourism niche for the destination (Berbel-Pineda et al., 2019). Food tourism creates opportunities and synergies for small producers including SMFEs with tourism-related businesses and contributes to reinforcing, enriching and differentiating a destination offering. Besides that, food tourism has started to be seen as a new opportunity for local producers to get in contact with consumers (Fanelli 2019; Folgado-Fernández et al., 2019). The practice of this emerging tourism typology can generate multiple benefits such as overcoming the obstacles experienced with the actual form of cooperation between the two sectors (diversification and food sourcing). Pérez and Pérez-Ferrant (2018) argue that food in tourism is much more than a business because of the way it influences and contributes to the construction, management, and growth of populations, societies, the environment, politics, reputations, innovation, and welfare.

Nevertheless, although food tourism will continue to generate employment, economic activity, to increase globalization of food, cultural identity and to create "culture vultures" (Okumus, 2020; Yeoman and McMahon-Beatte, 2016), a new approach must be implemented to ensure the survival and longevity of food tourism during the time of the crisis by increasing hedonistic production and experiences via digital transformations. Thus, food tourism should have an agenda that can advance scientific progress in tourism and to receive more attention on the adoptive technology and its effect on designing food tourism systems and experiences.

\section{Tourism and SMEs in the Age of Crisis: A Pandemic Perspective}

The paradox of crisis management in the pandemic era is that SMEs will actually fare better because they have had to weather the pandemic-storm. By adapting novel technology, they not only build resilience, they also set the stage for even further development. Several studies indicate that SMEs with dynamic and innovative capabilities who are willing to learn from crises, contain a tendency to recover quickly (Islam et al., 2021). Here, the process of learning can be executed informally through networking initiatives, mentoring, or coaching (Saunders et al., 2014) which hugely decreases the expenses involved. Moreover, Sheth (2020) also explains SME's interest in exploring business opportunities and integrating technology into 
their future growth process, which indicates a dynamic learning approach and adjustment from the crisis scenario. The COVID-19 calamity has put the resilience of many SMEs around the world to the test, as they have been forced to adapt to the pandemic-induced changes and adjust their business models swiftly to survive. This rapid and forced transition has generated many challenges for SMEs. The global crisis caused by the COVID-19 pandemic has shifted market dynamics. Therefore, firms are required to be responsive in order to successfully adapt to these changing market realities. Baralla et al (2020), tourism businesses must, therefore, be equipped with cutting-edge tools that, in a context of Smart Tourism, guarantee the originality of local products. Indeed, this kind of tourism can attract potential visitors, offering huge potential growth for local areas, cities, regional, and national economies.

At the same time, these tools explore new opportunities, due to their size and flexibility, (Shepherd \& Williams, 2018; Davidsson, 2015) and develop emergent strategies for sustainable business operations. Driven by the fact that the safety of SMEs is crucial for the global economy (Storey, 2016), it is important for SMEs to have plans in place for securing business continuity such as "identifying and managing the risks which threaten to disrupt essential processes and associated services, mitigating the effects of these risks, and ensuring that recovery of a process or service is achievable without significant disruption to the enterprise".

\section{Digital Technologies (DT) and SME}

The sense of optimism for tourism and food production was short-lived. Within a few months, the pandemic crisis dealt a severe blow to this high-flying industry when countries closed their borders and locked down their economies in the fight against the Coronavirus. Tourism is one of the most labour- intensive sectors. Such a slowdown for the industry may put millions of jobs at risk, thereby threatening to roll back the progress made on the front of sustainable development goals (World Tourism Organization, 2020). The pivotal role of technology is undeniably required to make the leap to recover and reinvent regional tourism. The focus is to emphasize the inclusion and integration of technologies for SME as Smith refers to (1994), it will allow the effective strategic operations of tourist distribution channels as smart and innovative tourism enables food producers to reposition themselves with other tourism players in the value chain and reach more tourists as compared to the traditional channels (Pinto et al., 2020).

Technology is driving a flexibility force in the tourism industry, especially in a volatile and uncertain environment (Hall, Scott and Gossling, 2020). Disasters, including the pandemic, help in speeding up changes in technology. In order to deal with the repercussions of extreme events like COVID-19, SMEs use, among other things, Digital technologies (DT). These include, for instance, mobile and collaborative technologies, the Internet with next-generation telecommunication networks, big- data analytics, artificial intelligence (AI) that uses deep learning, and blockchain technology. DTs digitalise and crosslink the value creation process. There is evidence in literature that the appropriate strategic adaptation of DT can lead to enhanced competitiveness, productivity, and performance (Chan, Teoh, Yeow, \& Pan, 2018; Kleis, Chwelos, Ramirez, \& Cockburn, 2011). Ultimately, In the time of crises, SMEs have taken aid from technology devices and experts. There are instances of robots replacing people, applications on mobiles being employed to track people's contacts, and Big Data analytics 
forecasting COVID-19 spread among the masses. Automation technologies and artificial intelligence can reduce cost, improve liquidity, and enhance flexibility for SMEs food production. This will also help maintain social distancing (Assaf \& Scuderi, 2020; Thomas \& Chopra, 2020), as technology can connect people without any physical contact. Thus, technology can handle pandemic-specific problems such as screening, discovering COVID-19 cases and tracking contacts etc. (Hall et al., 2020). Therefore, the SMEs sector is largely dependent upon technology and digital stimulus in order to transform food production strategic operation and to redesign best operational practices to benefit from the technological paradigm-shifts experienced in food tourism (Buhalis, 2019). Buhalis also posits that all suppliers, stakeholders and intermediaries, the public sector, as well as consumers, are becoming dynamically networked, which co-produces value for everybody interconnected within the smart and innovative ecosystem.

Despite the significance of using DTs for securing SMEs continuity during extreme disruptions (and hence COVID-19), there is limited to no guidance for SMEs on how to prepare organisations for such disruptions. Past contributions are confined in the subfields of security, IT-enabled operations, and IT strategy (Niemimaa, 2015). Furthermore, how could SMEs organise their work based on DTs as a response to possible incidents (and in this case, to COVID-19)? This concern shows that technology is a major force in creating flexibility in the tourism industry (Hall et al., 2020). Disasters help in speeding up changes in technology. During COVID-19, people have taken massive aid from technology experts. Many reports show a surge in the public's trust in technology, their readiness to connect, and their willingness to change their attitudes toward technology. To add, the general public have now started ignoring privacy issues to get a more significant technology benefit (Stankov et al., 2020). Gretzel et al. (2020) has presented the "six transformative e-tourism research pillars" for bringing in changes in e-tourism by proactively using IT resources for short-term and longterm purposes. Along the same line, in the post-pandemic recovery phase, the integration of DTs and SMEs would improve cooperation between producers and tourists, help reconnect consumers with producers, and lead to better understanding between urban and rural residents. The conceptual model of tourism production and DTs would confirm that producers can carefully decide their market objective and where and how to sell which products, which enables producers' participation in a new form of tourism ecosystem (Dreyer et al, 2016).

\section{Integrated Tourism Production Model}

The foundation of the conceptual model is built on two substantial factors: food production and DT. This proposed model affirms that tourism is driven by producers, intermediaries (e.g. technology) and experience which supports the ideas of Morris and Young (2000) who conclude that collaboration between intermediaries and tourism has been adopted to update modern market orientation and to respond more proactively to consumer demand for products which offer specific qualities and added value. A recent report (Chamarro, 2020) indicates that information technology employed extensively during the pandemic by individuals will define how individual lives are transformed after the pandemic has passed. The combined effect of industry 4.0 and the current COVID-19 pandemic has led to some rapid changes in tourism. To add, tourism 4.0 greatly reduces the adverse impacts caused by the industry such as transportation carbon emission; moreover, there is a need to utilise information technology to enhance the tourist experience (Peceny, Urbančič, Mokorel, Kuralt \& Ilijaš, 2019). 
As shown in Figure 1, Smith (1994) sets out a model of the tourism production function, which indicates how tourism production requires the active involvement of consumers. Smith argues that tourism is not an 'industry' in the conventional sense because there is no single production process, no homogeneous product, and no location confined market. The production process, as shown in Figure 1, does not overlap with other initial concepts developed by other researchers but, interestingly, it defines certain identical similarities with Torres' (2003) work on the important aspects of demand- related factors in defining tourism and production linkages.

Figure 1: Tourism Production Process

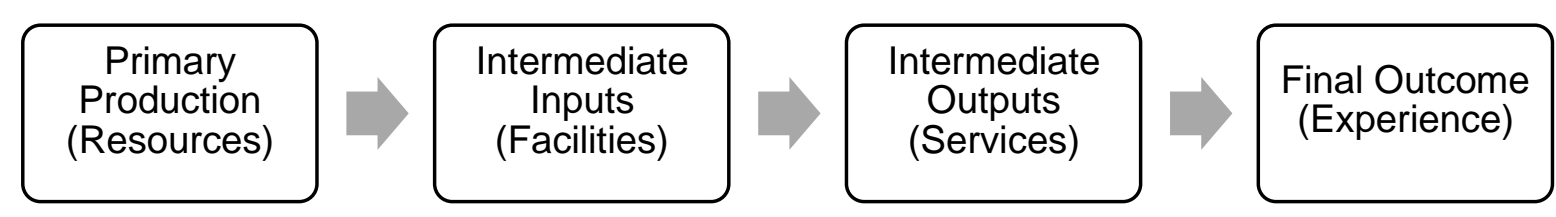

Source: Smith (1994: 591)

The model consists of four distinct elements: primary inputs (resources exploitation); intermediate inputs (facilities to convert the resources into a product); intermediate outputs (tourism services to commercialize the product); and final outcome (tourist experience generated from product involvement activities). Each stage incorporates the transferable aspects of physical plant, service and hospitality, and freedom of choice and involvement. By outlining a generalised production process in tourism, Smith (1994) depicts strategic approaches to how producers and destinations move through various stages to penetrate the tourism market. In this study, it is important to stress that this understanding of production in tourism is not an attempt to provide yet another food tourism typology.

On the other hand, it can be seen that the production process in food tourism is conceptually equivalent to the production of a tourism experience. It is also connected to the collective effort of a number of actors and food producers which are increasingly an integral part of destination development across the world (Andersson et al., 2017). The research builds on the work of Härting, Reichstein, Härtle and Stiefl (2017) showing that there are changes and potentials due to digitization in the tourism industry in general. The authors hypothesize that as digitalization progresses, not only business processes within the company change, but also customer needs that have to be taken into account in the digital transformation of a company. The objective of this study is to show the potential of changing customer needs in a digital world in tourism from managers' perspectives. Therefore, through the conceptual model, authors present recommendations for action by the tourism industry in order to not only gain a deeper insight into customer needs, but also to provide more customer-oriented services. Based on the study, using the Grounded Theory, the authors designed a conceptual model (Figure 2), demonstrating the potential of changing needs in a digital world in tourism. 
Figure 2: Conceptual Model on the Potentials of Digitization in Tourism

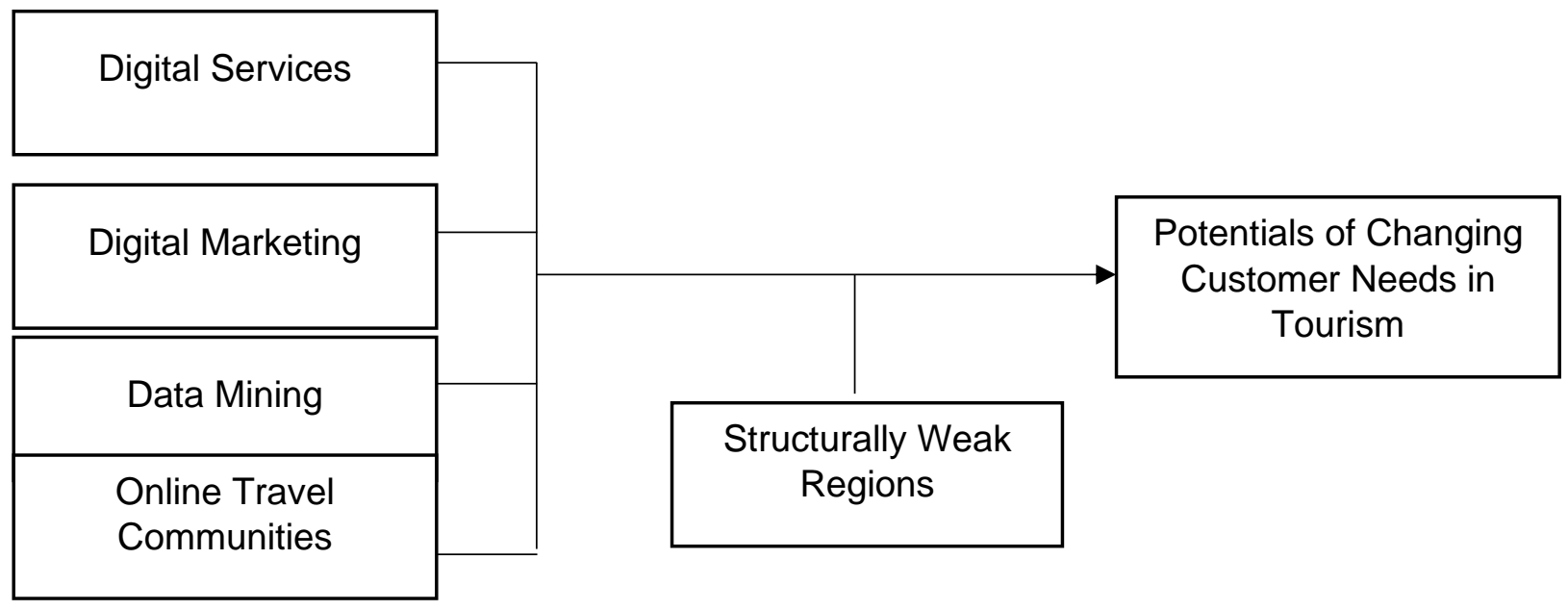

Source: Reichstein and Härting (2018: 1487)

The above model is constructed based on six elements: digital services (digital interaction within the customer journey), digital marketing (target group-specific marketing through social media, "Influencer" and "Blogger" and personalized customer approach through digital marketing), data mining (personalized offers through comprehensive analysis of customer data and improvement of service quality), online travel communities (trusted information channel, influencing customer behaviour and possibility to improve the tourist services offered by analysing the customer evaluations), structurally weak regions (additional digital services, digital reporting on information trips and digital communication with customers), and potential of changing customer needs (digital provision of information).

Figures 1 and 2 present a unified concept to provide a preliminary understanding of the interrelationships between production and digital. Smith's (1994) model is selected because his model provides a clear and explicit concept of the product in tourism, from the planning, development, and management aspects until the final stage that is delivery. In addition, the extent of Reichstein's and Härting's (2018) concept on digitization of tourism could further validate the collaborative approach in re-defining how producers, consumers, and suppliers should not be conceptualized as separate entities; and how a tourism approach based upon food chains or systems permits us to develop a more sophisticated understanding of the discourses and practices surrounding the issue of local food (Sims, 2010).

The development of the framework allows SMFEs to cope with changes in demand caused by digitization in order to strengthen the competitive position. SMFEs can, for example, benefit sustainably through the use of data mining, which enables a personalized customer approach by integrating social media, inherent influencers, and bloggers. However, companies must digitally process their products and services to increase customer appeal and loyalty. The elaboration recommends that tourism providers digitally monitor the entire customer journey of their clients, as well as monitor digital applications and communication tools so new opportunities to reach customers to meet their changing needs, will be grasped.

\section{Conclusion and Recommendation}

The future of tourism is here. The inclusion of technology and digital advances have been accelerated by the coronavirus, requiring society, the economy, and nation to look towards the future with much more speed. Technology and digital ecosystems are part of the smart 
tourism initiative in order to strengthen tourism-generated innovative development in cities and their surroundings including socio-economy. Food tourism is a sub-sector that can not only mitigate pandemic impacts, but also can take a step forward to a more sustainable mode of tourism recovery. Moreover, it is a crucial mechanism towards solutions in social initiatives including the creation of jobs and improving quality of life by paving the way towards both new and existing technologies, and innovative processes that allow for both a more efficient production as well as better goods and services. These are all key drivers for economic growth. Overall, an effective and newly developed food tourism production model can co-create (stakeholders) distinctive solutions which will propel them to reinvent national tourism.

The inclusion of production and digital technology justify the concerns of Boesen et al (2017) who identify that locally produced food has not been successfully related to tourism. These authors also mention that the conditions for successful collaboration in tourism networks, particularly network-collaboration between food production and tourism actors, have not been explored in-depth. While this thesis has explored many key issues, it raises several important considerations that could form the basis for future investigations. Nonetheless, further research is required to determine the efficacy of food as a destination's primary capital to be 'invested' in tourism which generates more added-value products, prompts destination development, and increases socio-economic wellbeing.

The crisis is an opportunity to rethink tourism for the future. Aiming to provide such measures for SMFEs, capitalising on Digital Technologies (DT) for food tourism sector in a form of integrated model will provide more sustainable and resilient for tourism development. The newly developed model will signpost to an urgent need to diversify and strengthen the resilience of the tourism economy post COVID-19. This study will be the foundation for SMFEs to foster and convert this crisis into transformative innovation and how to conduct research and development (R\&D) that can enable, inform and reshaping the production system for future use especially in the time of crisis.

Overall, the anticipated outcome of the model would create a direction for local food businesses to better prepare for future shocks and, to address long standing structural weaknesses, and encourage the digital transformations that will be essential to shift to more reliable and sustainable model of tourism development. In the same vein, the model would redefine the function of stakeholders and government, that serve as a platform for more robust risk and crisis response mechanism setting of a next normal, and closer co-ordination to revive food tourism sector. These are three (3) main areas of the expected outcomes of this study:

i. Establish new concept and knowledge on adoptive Digital Technologies (DT) in the SMFEs production system in managing and mitigating current and future crises.

ii. Develop a new integrated model that will be beneficial for SMFEs and other stakeholders in revitalising food tourism development through systematic network, and to build a longterm resilience and growth for food sector in tourism.

iii. Contribute to the body of knowledge on the interplay between food tourism and digital and technology ecosystem, which is a new area to be explored in tourism research. 


\section{References}

Assaf, A., \& Scuderi, R. (2020). COVID-19 and the recovery of the tourism industry. Tourism Economics.

Baralla, G., Pinna, A., Tonelli, R., Marchesi, M., \& Ibba, S. (2021). Ensuring transparency and traceability of food local products: A blockchain application to a Smart Tourism Region. Concurrency and Computation: Practice and Experience, 33(1), e5857.

Berbel-Pineda, J. M., Palacios-Florencio, B., Ramírez-Hurtado, J. M., \& Santos-Roldán, L. (2019). Gastronomic experience as a factor of motivation in the tourist movements. International Journal of Gastronomy and Food Science, 18.

Buhalis, D. (2019). Technology in tourism-from information communication technologies to eTourism and smart tourism towards ambient intelligence tourism: a perspective article. Tourism Review, 75(1), 267-272.

Bundy, J., Pfarrer, M. D., Short, C. E., \& Coombs, T. (2017). Crises and crisis management: Integration, interpretation, and research development. Journal of Management, 43(6), 1661-1692.

$\mathrm{Bu}$, Y., Parkinson, J., \& Thaichon, P. (2021). Digital content marketing as a catalyst for e-WOM in food tourism. Australasian Marketing Journal, 29(2), 142-154.

Härting, R. C., Reichstein, C., Härtle, N., \& Stiefl, J. (2017). Potentials of digitization in the tourism industry-empirical results from German experts. In International Conference on Business Information Systems (pp. 165-178). Springer, Cham.

Chan, C. M. L., Teoh, S. Y., Yeow, A., \& Pan, G. (2018). Agility in responding to disruptive digital innovation: Case study of an SME. Information Systems Journal, 29(2), 436-455.

Chan, S. M. (2020). Get Ready for a Post MCO Reset. The Star. Retrieved from https://www.thestar.com.my/business/business-news/2020/05/01/get-ready-for-apost-mco-rese

Cucculelli, M., \& Peruzzi, V. (2020). Innovation over the industry life-cycle. Does ownership matter? Research Policy, 49(1).

Davidsson, P. (2015). Entrepreneurial opportunities and the entrepreneurship nexus: A reconceptualization. Journal of Business Venturing, 30(5), 674-695.

Dreyer, H. C., Strandhagen, J. O., Hvolby, H. H., Romsdal, A., \& Alfnes, E. (2016). Supply chain strategies for speciality foods: A Norwegian case study. Production Planning and Control, 27(11), 878-893.

Fanelli, R. M. (2019). Seeking gastronomic, healthy, and social experiences in tuscan agritourism facilities. Social Sciences, 9(2).1-15.

Fath, B., Fiedler, A., Sinkovics, N., Sinkovics, R. R., \& Sullivan-Taylor, B. (2021). International relationships and resilience of New Zealand SME exporters during COVID-19. Critical Perspectives on international Business, 1742-2043.

Folgado-Fernández, J. A., Campón-Cerro, A. M., \& Hernández-Mogollón, J. M. (2019). Potential of olive oil tourism in promoting local quality food products: A case study of the region of Extremadura, Spain. Heliyon, 5(10), e02653.

Hall, C. M., Prayag, G., \& Amore, A. (2017). Tourism and resilience. Channel View Publications. Hall, C. M., Scott, D., \& G ossling, S. (2020). Pandemics, transformations and tourism: Be careful what you wish for. Tourism Geographies, 22(3), 577-598.

Institute for Democracy and Economic Affairs Malaysia. (2020). Tourism Recovery Plan: An Opportunity for Change Post COVID-19. https://www.ideas.org.my/wpcontent/uploads/2020/09/B28_Tourism_V3.pdf 
Kleis, L., Chwelos, P., Ramirez, R. V., \& Cockburn, I. (2011). Information technology and intangible output: The impact of IT investment on innovation productivity. Information Systems Research, 23(1), 42-59.

Mayr, S., Mitter, C., \& Aichmayr, A. (2017). Corporate crisis and sustainable reorganization: Evidence from bankrupt Austrian SMEs. Journal of Small Business Management, 55(1), 108-127.

Mkono, M., \& Tribe, J. (2017). Beyond reviewing: Uncovering the multiple roles of tourism social media users. Journal of Travel Research, 56(3), 287-298.

Niemimaa, M. (2015). Interdisciplinary review of business continuity from an information systems perspective: Toward an integrative framework. Communications of the Association for Information Systems, 37(4), 69-105.

Okumus, B. (2020). Food tourism research: a perspective article. Tourism Review, 76(1), 3842.

Pérez, R. A., \& Pérez-Ferrant, A. (2018), Towards a new strategic paradigm, in Moutinho, L. and Vargas-S anchez, A. (Eds), Strategic Management in Tourism. CABI: Wallingford.

Peceny, U. S., Urbančič, J., Mokorel, S., Kuralt, V., \& Ilijaš, T. (2019). Tourism 4.0: challenges in marketing a paradigm shift. In Consumer Behavior and Marketing. IntechOpen.

Pinto, A. S., Costa, E., Borges, I., Silva, F., \& Abreu, A. (2020). Virtual accessibility on digital business websites and tourist distribution. Advances in Tourism, Technology and Smart Systems, 171, 93-103.

Randall, W. (2018). Leadership, strategy, and management. A qualitative study of crisis survival Unpublished PhD Thesis. Capella University.

Reichstein, C., \& Härting, R. C. (2018). Potentials of changing customer needs in a digital world-a conceptual model and recommendations for action in tourism. Procedia Computer Science, 126, 1484-1494.

Robinson, R. N., \& Getz, D. (2014). Profiling potential food tourists: An Australian study. British Food Journal, 116(4), 690-706.

Saunders, M. N., Gray, D. E., \& Goregaokar, H. (2014). SME innovation and learning: the role of networks and crisis events. European Journal of Training and Development, 38(1-2), 136-149.

Shepherd, D. A., \& Williams, T. A. (2018). Spontaneous venturing: An entrepreneurial approach to alleviating suffering in the aftermath of a disaster. MIT Press. Sheth, J. (2020). Impact of Covid-19 on consumer behavior: Will the old habits return or die. Journal of Business Research, 117, 280-283.

Sidhu, K. K. (2020). Covid-19 brings about mass digital adoption. Digital News Asia. Retrieved from https://www.digitalnewsasia.com/digital-economy/covid-19-brings-about-massdigital-adoption

Sigala, M. (2020). Tourism and COVID-19: Impacts and implications for advancing and resetting industry and research. Journal of Business Research, 117, 312-321.

Smith, S. L. (1994). The tourism product. Annals of tourism research, 21(3), 582-595. Sotiriadis, M. D. (2015). Culinary tourism assets and events: Suggesting a strategic planning tool. International Journal of Contemporary Hospitality Management, 27(6), 1214-1232

Storey, D. J. (2016). Understanding the small business sector. Routledge library editions: Small business. Milton Park, Abingdon, Oxon: Routledge. 
Thomas A., Chopra M. (2020) On How Big Data Revolutionizes Knowledge Management. In: George B., Paul J. (eds) Digital Transformation in Business and Society. Palgrave Macmillan, Cham.

World Tourism Organization. (2020). International tourism numbers could fall 60-80\% in 2020 [Press Release. https://www. unwto.org/news/covid-19-international-touristnumbers-could-fall-60-80-in-2020.

Yeoman, I., \& McMahon-Beatte, U. (2016). The future of food tourism. Journal of Tourism Futures, 2(1), 95-98. 